\title{
Challenges Facing Airway Epithelial Cell-Based Therapy for Cystic Fibrosis
}

\author{
Andrew Berical1,2, Rhianna E. Lee ${ }^{3}$, Scott H. Randel/ ${ }^{3,4}$ and Finn Hawkins ${ }^{1,2 *}$ \\ ${ }^{1}$ Center for Regenerative Medicine, Boston Medical Center and Boston University, Boston, MA, United States, \\ ${ }^{2}$ The Pulmonary Center, Boston University School of Medicine, Boston, MA, United States, ${ }^{3}$ Cystic Fibrosis Research \\ Center, Marsico Lung Institute, University of North Carolina at Chapel Hill, Chapel Hill, NC, United States, ${ }^{4}$ Department \\ of Cell Biology and Physiology, University of North Carolina at Chapel Hill, Chapel Hill, NC, United States
}

Mutations in the cystic fibrosis transmembrane conductance regulator (CFTR) gene cause the life-limiting hereditary disease, cystic fibrosis (CF). Decreased or absent functional CFTR protein in airway epithelial cells leads to abnormally viscous mucus and impaired mucociliary transport, resulting in bacterial infections and inflammation causing progressive lung damage. There are more than 2000 known variants in the CFTR gene. A subset of CF individuals with specific CFTR mutations qualify for pharmacotherapies of variable efficacy. These drugs, termed CFTR modulators, address key defects in protein folding, trafficking, abundance, and function at the apical cell membrane resulting from specific CFTR mutations. However, some CFTR mutations result in little or no CFTR mRNA or protein expression for which a pharmaceutical strategy is more challenging and remote. One approach to rescue CFTR function in the airway epithelium is to replace cells that carry a mutant CFTR sequence with cells that express a normal copy of the gene. Cell-based therapy theoretically has the potential to serve as a one-time cure for CF lung disease regardless of the causative CFTR mutation. In this review, we explore major challenges and recent progress toward this ambitious goal. The ideal therapeutic cell would: (1) be autologous to avoid the complications of rejection and immune-suppression; (2) be safely modified to express functional CFTR; (3) be expandable ex vivo to generate sufficient cell quantities to restore CFTR function; and (4) have the capacity to engraft, proliferate and persist long-term in recipient airways without complications. Herein, we explore human bronchial epithelial cells (HBECs) and induced pluripotent stem cells (iPSCs) as candidate cell therapies for CF and explore the challenges facing their delivery to the human airway.

Keywords: cystic fibrosis, cell-based therapy, induced pluripotent stem cells, human bronchial epithelial cells, engraftment

\section{INTRODUCTION}

Cystic fibrosis (CF) is an autosomal recessive, multisystem, genetic disease caused by mutations in the cystic fibrosis transmembrane conductance regulator (CFTR) gene resulting in deficient and/or defective CFTR protein (Cutting, 2014; Ratjen et al., 2015). CFTR is an anion channel present across a number of epithelia including the lungs, intestine, sinuses, pancreas, biliary tree, and vas deferens. The consequences of CFTR dysfunction are pronounced in the lungs where ineffective 
chloride and bicarbonate ion transport results in an abnormally viscous and acidic apical surface layer (ASL). This abnormal environment is colonized by bacteria in early life and a cycle of infection and inflammation results in bronchiectasis and end-stage lung disease (Ratjen et al., 2015). Disease severity is determined to a large extent by the causative CFTR mutation(s). Over 2,000 variants in CFTR have been described, of which approximately 300 have been determined to be pathogenic (cftr2.org). These variants or combinations of variants have differing effects on the amount and function of CFTR protein. Some variants are associated with milder disease or particular organ involvement while others may be associated with very severe disease. For classification purposes, these mutations are grouped into six classes (I-VI) based on their effect on CFTR including: no protein synthesis (class I), protein misfolding (class II), dysfunctional channel gating (class III), reduced conductance (class IV), insufficient CFTR protein due to abnormal RNA splicing (class V), or increased protein turnover (class VI).

Mucus clearance techniques, antibiotics, and lung transplantation significantly improve the life expectancy of CF individuals. The recent discovery of CFTR modulators has ushered in a new era of precision medicine for CF patients with mutations that result in some residual druggable CFTR protein. For example, the major defect in patients with the class III mutation G551D is diminished channel activity at the apical surface. Ivacaftor is an FDA approved CFTR potentiator that increases CFTR activity and results in clinical improvement in patients with at least one copy of the G551D mutation (Ramsey et al., 2011). F508del is the most common CFTR mutation affecting approximately 90\% of CF patients (Cutting, 2014). This mutation results in defective folding and trafficking of the CFTR protein. Corrector molecules such as lumacaftor and tezacaftor in conjunction with ivacaftor result in increased CFTR activity and some clinical improvement though not as robust as the response of gating and residual function mutations to ivacaftor therapy (Rowe et al., 2017; Taylor-Cousar et al., 2018). Recent progress with "triple combination" regimens including two correctors plus the potentiator ivacaftor indicates increased efficacy for those harboring the class II F508del mutation (Davies et al., 2018; Keating et al., 2018). Class I mutations are non-sense, frameshift or splice variants that result in premature termination of the CFTR transcript and no CFTR protein. These patients currently have no targeted therapies available and there are many barriers to a pharmacological approach to treatment.

The challenge is clear, how do we identify and develop effective therapies for all CF individuals? In theory, replacing the mutant CFTR sequence with the normal sequence could restore CFTR function regardless of mutation. Generally, this might be achieved by one of three approaches: (1) in vivo delivery of normal CFTR sequence, e.g., via viral vectors, (2) in vivo editing of the mutant CFTR sequence or, (3) delivery of cells carrying the normal CFTR sequence to replace cells carrying the mutant sequence. In this review, we focus on the approach of cellbased therapy for CF lung disease. Although there are compelling examples of effective cell-based therapies, such as hematopoietic stem cell transplantation, there are many challenges facing such an approach for lung disease. What cell type is best suited to restore CFTR function to the airways? How might cells be effectively but safely delivered to a CF patient's lungs? Here we will review the most promising cellular candidates to treat CF, human bronchial epithelial cells (HBECs) and induced pluripotent stem cells (iPSCs). Finally, we will discuss the major hurdles facing the field of CF cell-based therapeutics, including delivery and engraftment of cells into a diseased host.

\section{OVERVIEW OF AIRWAY EPITHELIAL BIOLOGY IN CF}

Airway epithelial cells, including club, goblet, multi-ciliated, basal and neuroendocrine cells occupy a vital environmental interface. Their normal physiological function is essential to maintain respiratory tract health, and the cells are intimately involved in the pathogenesis of multiple respiratory tract maladies, including the common diseases asthma and chronic obstructive pulmonary disease (Randell et al., 2009). In CF, a dehydrated and acidic ASL impairs critical innate defense mechanisms including mucociliary clearance (Randell et al., 2006; Button et al., 2012; Stoltz et al., 2015). There is current debate on the airway cell types that express CFTR, but it is detected in the submucosal glands (Jiang and Engelhardt, 1998) of the airway and in certain surface epithelial cells including multi-ciliated cells (low expression) and in the recently described pulmonary ionocyte (high expression) (Jiang and Engelhardt, 1998; Montoro et al., 2018; Plasschaert et al., 2018). There is debate whether cell autonomous loss of CFTR is hyper-inflammatory per se, but the combination of mucus stasis and chronic infection clearly results in highly inflamed CF airways (Roesch et al., 2018). Complex interactions during infection stemming from the epithelial defect ultimately cascade into pathologic changes including extensive mucus obstruction, ectasis of bronchi and bronchioles, and consequent loss of pulmonary function (Figure 1). It is likely that significant structural damage to the airways and surrounding parenchyma becomes irreversible, and a goal for airway epithelial cell therapy is to intervene early, likely in childhood.

\section{HUMAN BRONCHIAL AND BRONCHIOLAR EPITHELIAL CELLS (HBECS)}

Epithelial cell proliferation in the lung is relatively quiescent at steady state, but this organ retains the ability to regenerate rapidly after injury (Hegab et al., 2012). Much has been learned in recent years about lung stem cells and their roles in repair and regeneration, with particular emphasis on the alveolar parenchyma (Hogan et al., 2014; Kotton and Morrisey, 2014). Cell-based therapy for CF will logically be focused on the conducting airway epithelium, the primary site for mucus stasis, infection, and inflammation. The airways harbor distinct cell populations along the proximal to distal axis that exhibit selfrenewal and differentiation capacity. Here, we propose that HBECs may serve as candidates for autologous cell therapy of CF. We review the stem cell properties of HBECs with 

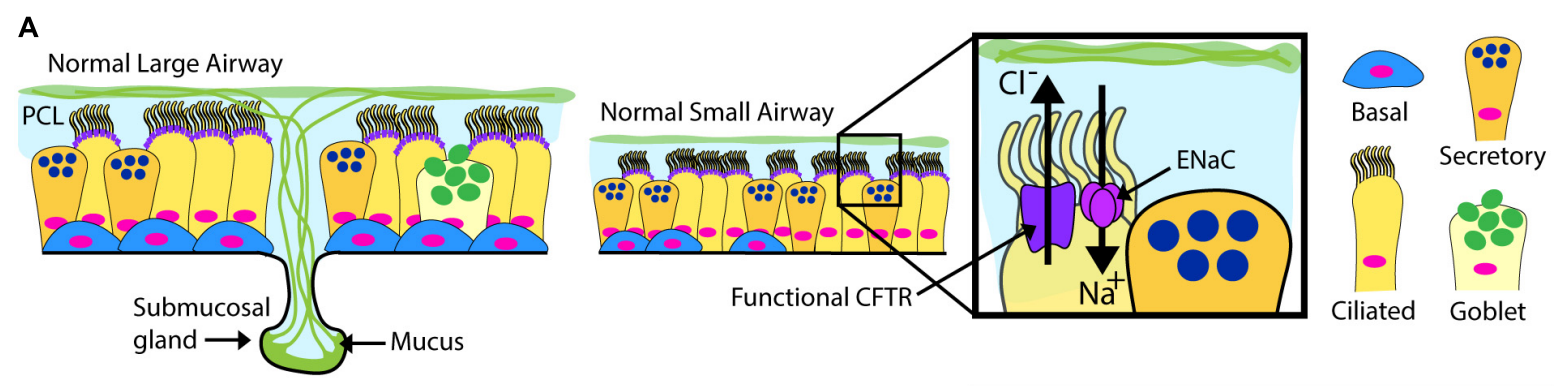

B
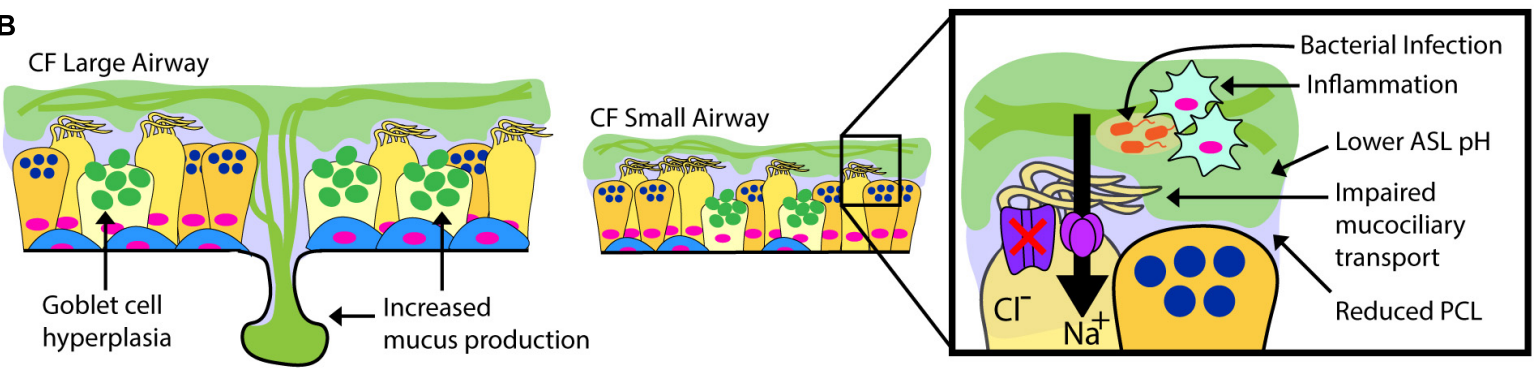

FIGURE 1 | Normal vs. CF Airway. Schematic drawings of normal and CF airways, illustrating selected components of epithelial apical ion transport. (A) Secreted mucins are produced by submucosal glands in the large airways and surface goblet cells, forming the overlying, mucin-rich component of the airway surface layer (ASL). This layer is normally transported by effective beating of cilia in the periciliary layer (PCL). ASL hydration is largely controlled by the balance of chloride secretion through CFTR and sodium reabsorption by the epithelial sodium channel (ENaC). (B) Mucin overproduction from hypertrophic submucosal glands and hyperplastic surface goblet cells characterize the CF large airways. Non-functional or absent CFTR leads to diminished chloride transport and increased sodium transport through ENaC. Airway dehydration reduces the PCL, impairing mucociliary transport. Accumulation of thick, sticky mucus increases overall ASL thickness and promotes a low pH environment favoring chronic bacterial infection and inflammation. The CF ASL environment is a likely barrier for cell therapy.

a focus on the unique advantages and challenges posed for therapeutic translation.

\section{STEM CELLS IN THE CONDUCTING AIRWAYS}

The human conducting airways are composed of a pseudostratified epithelium extending from the trachea to the proximal end of small bronchioles. The predominant evidence is that basal cells are the stem cells in this region (Rock et al., 2009). Basal cells are relatively undifferentiated and express a number of classic markers including TP63 and KRT5. The regenerative capacity of basal cells has been extensively demonstrated through in vitro clonal growth assays, tracheal graft regeneration, and in vivo lineage tracing studies (Gray et al., 1991; Liu et al., 1994; Hong et al., 2004; Rock et al., 2009). Basal cells have the capacity to differentiate into the major cell types of the conducting airways including club (previously Clara) cells (Schoch et al., 2004; Rock et al., 2009), pulmonary neuroendocrine cells (Montoro et al., 2018), the recently described pulmonary ionocyte (Montoro et al., 2018; Plasschaert et al., 2018), and serous and mucus cells in the glands (Hegab et al., 2012, 2014). It is thought that ciliated and goblet cells are generated through a club cell intermediate (Tata et al., 2013; Widdicombe and Wine, 2015), but recent single cell mRNA sequencing studies also suggests direct differentiation of basal cells into ciliated cells (Plasschaert et al., 2018). Basal cell differentiation into pulmonary ionocytes and ciliated cells (either directly or indirectly) is of particular interest for CF cell therapy as these cell types express CFTR and are primarily responsible for epithelial ion transport (Rock et al., 2009; Montoro et al., 2018). The ability of lung basal cells to self-renew and replace luminal CFTR-expressing cell types is vital for cell therapy to be long-lasting.

The basal cell population is likely heterogeneous, containing subpopulations with different proliferation and differentiation capacities. At steady state, basal cell subsets express early differentiation markers for club or ciliated cells including the intracellular domain of Notch2 (N2ICD) or the protooncogene transcription factor MYB (C-Myb), respectively, suggesting subpopulations already primed for differentiation (Pardo-Saganta et al., 2015; Watson et al., 2015). Mechanisms regulating lung cell development, homeostatic maintenance, and repair have been recently reviewed (Lee and Rawlins, 2018). However, there is still debate about which cell lineage model is most applicable to the human pseudostratified airway epithelium. Are there rare populations of stem cells in specific niches that undergo asymmetric divisions, generating committed downstream progenitors, or is the stem cell compartment more widely distributed and stochastically regulated? While cell harvesting, gene correction, expansion, and delivery of intermediate progenitors may be efficacious, it is logical that starting with cells exhibiting extensive growth potential and differentiation capacity would be advantageous. Thus, identifying basal cell subsets and gene signatures corresponding to high clonal growth capacity remains an important goal that will theoretically serve as the basis for efficacious CF cell therapy. 
Additional cell types within the airways should be considered as alternative candidates to restore CFTR function to the epithelium. Columnar epithelial cells from the pseudostratified regions demonstrate extensive plasticity in which they can dedifferentiate into basal cells (Tata and Rajagopal, 2017). Studies in the porcine model of CF suggest the importance of submucosal gland dysfunction in CF pathogenesis (Hoegger et al., 2014) and lineage tracing in mice illustrates a key role for gland myoepithelial cells in repair (Lynch et al., 2018; Tata et al., 2018). The ability to access, propagate and correct human gland myoepithelial cells, and their ultimate return to gland tubular and acinar niches will require more study.

\section{OBTAINING, EXPANDING, AND GENE CORRECTING HBECS}

Conceptually, HBECs can be obtained from the lungs of CF individuals using one of three minimally invasive techniques, induced sputum sample collection, bronchiolar lavage, and endobronchial brushing or biopsy. These methods yield approximately $2 \times 10^{3}, 5.5 \times 10^{3}$, and $2 \times 10^{6}$ cells, respectively (Mou et al., 2012; Pollock et al., 2013; Butler et al., 2016). Considering how few cells effectively engraft by current approaches, the paucity of HBEC starting materials poses a considerable challenge to their use in cell therapy. As such, autologous cell-based therapy for CF with somatic epithelial cells will likely require in vitro culture for both cell expansion and gene correction. Fortunately, there is a long history of cell culture techniques to expand and subsequently differentiate a predominantly basal cell population from mouse and human large airways (see Table $\mathbf{1}$ and Bove and Randell, 2015). Conventional expansion methods can be augmented to increase population doublings using dual SMAD inhibition or Rho kinase inhibition along with irradiated mouse 3T3-J2 fibroblasts co-culture (Suprynowicz et al., 2012; Mou et al., 2016). Key reagents such as irradiated 3T3-J2 feeder cells and irradiated serum developed for keratinocytes have been approved for clinical applications by some regulatory authorities and can be, similarly, employed in modern protocols to expand primary HBECs (Suprynowicz et al., 2012; Gentzsch et al., 2017).

While the larger airways are lined by a tall pseudostratified epithelium the more distal bronchi and bronchioles are lined by a progressively shorter epithelium, in which basal cells eventually extinguish. In the last generations of the small airways, the epithelium becomes simple columnar to cuboidal where stem cells are thought to be contained in the club cell compartment, with an independent lineage existing among pulmonary neuroendocrine cells (Hogan et al., 2014), although pulmonary neuroendocrine cell generation of club and ciliated cells has been observed (Song et al., 2012). This distal region is an important target since small airway obstruction and air trapping is thought to be a defining feature of early CF (Rosenow et al., 2017). Culture methods for human small airway epithelial cells are less well developed than for the large airway, and cells of the smallest bronchioles appear to be more dependent on mesenchymal signals (Lee et al., 2017; Zepp et al., 2017). Specific

TABLE 1 | Key studies in the development of culture methods for HBECs and directed differentiation protocols to derive airway epithelial cells from iPSCs.

\section{Human bronchial epithelial cell culture \\ Reference}

\section{methods}

Clonal growth of human bronchial epithelial cells

Detailed description of a media for proliferation of human bronchial epithelial cells on plastic

Differentiation of serially passaged cells at an

air-liquid interface (ALI)

Current detailed methods for ALI cultures using proprietary reagents

Current detailed methods for ALI cultures using non-proprietary reagents

Detailed methods for Conditionally Reprogrammed Cells (CRC, with feeder cells)

Dual SMAD inhibition method for cell expansion

Method allowing clonal expansion of CRC primary HBECs

CRC method with proprietary media and no feeder cells

Derivation of human airway epithelial cells from iPSCs

TGF $\beta$ /BMP inhibition required to generate anterior foregut endoderm from iPSC

Differentiation of human CF iPSCs into airway epithelial cells

Efficient differentiation of human iPSCs into lung epithelial cells comprised of both proximal and distal epithelial cells

Generation of multiciliated cells from human iPSCs Human iPSC-derived lung organoids composed of epithelium and mesoderm

Surface marker sort method (Carboxypeptidase M) and culture conditions to generate neuroendocrine and functional multiciliated cells

Fluorescent lineage reporters to purify early lung progenitors and generate epithelial-only organoid Wnt withdrawal after early lung specification required for airway patterning

Engraftment of iPSC-derived similar to embryonic lung-tips into immunocompromised mouse lungs

efforts to better understand human small airway stem cells, their propagation, and eventual engraftment are required.

There have been tremendous advances in genome editing techniques in the last decade, including zinc-finger nucleases, transcription activator-like effector nucleases (TALENs), and the clustered regularly interspaced short palindromic repeats (CRISPR)/Cas9 technique (Zhang et al., 2014). While of utmost importance for correcting a monogenic but complex lung disease such as CF, optimal methods for CFTR gene correction of HBECs with minimal off target, potentially carcinogenic risks, followed by cell expansion that maintains long-lived basal stem cells remain to be determined.

\section{INDUCED PLURIPOTENT STEM CELLS (iPSCS)}

iPSCs have several features relevant to their suitability as a source for cell-based therapies. Pluripotency refers to the 
capacity to differentiate into all cell types in the body. iPSCs can now be routinely generated from any human while retaining an individual's unique genetic information, without the need for an invasive procedure. The capacity of these cells to proliferate while retaining pluripotency means sufficient numbers for cell-based therapy might someday be feasible. In the following section we review the essential studies that made the discovery of iPSCs possible, summarize the recent progress in deriving lung epithelial cells from iPSCs (Table 1), particularly cell types relevant to $\mathrm{CF}$, and finally highlight the many challenges to be addressed before these cells can be transplanted into CF recipients.

\section{HISTORY OF IPSCS}

In 2006, Takahashi and Yamanaka made the remarkable discovery that the overexpression of four key factors in somatic cells could "re-program" cells into iPSCs (Takahashi and Yamanaka, 2006; Takahashi et al., 2007). This breakthrough was made possible by decades of prior work in the field of embryonic stem cells (ESCs) that identified: (1) the transient presence of a population of pluripotent stem cells in the developing embryo, (2) the culture conditions sufficient to capture, in vitro expand, and maintain the pluripotency of cells isolated from early embryos, and (3) the gene-regulatory networks that control the ground-state of pluripotency (Solter et al., 1970; Stevens, 1970; Evans and Kaufman, 1981; Smith, 2001). Given the regenerative potential of ESCs there was much initial enthusiasm for their therapeutic promise but also controversy over the ethical and moral considerations regarding the use of fetal tissue. From a scientific perspective the main drawback for using ESCs as a cell-based therapy was that even if the cell type of interest could be generated efficiently and safely, the cells would be allogeneic to the recipient and the issues of rejection and immunosuppression that limit the effectiveness of solid organ transplants would persist. Dr. Jim Gurdon's pioneering nuclear transfer experiments in the 1960s first suggested the feasibility of reprogramming a somatic cell into an autologous pluripotent stem cell (Gurdon, 1962). When a frog egg nucleus was replaced with an intestinal cell nucleus a viable tadpole was produced confirming that the cellular identity could be "reset" to a pluripotent state. Takahashi and Yamanaka set about screening candidate factors that might have the same effect. They identified four factors, Oct4, Sox2, Klf4, and $c-M y c$ that were sufficient to reprogram mouse somatic cells (initially skin fibroblasts) into pluripotent stem cells. These "induced" pluripotent stem cells were virtually indistinguishable from ESCs based on their similar transcriptional profiles and capacity to differentiate into all three germ layers when injected subcutaneously in a teratoma assay. Remarkably, iPSCs also contributed to embryogenesis when injected into a blastocyst. One year later, the same four factors were confirmed to reprogram human fibroblasts into iPSCs. Crucial to the emerging field of regenerative medicine, iPSCs have four key characteristics: (1) they are generated from the potential recipient, i.e., autologous, (2) they provide an unlimited supply of pluripotent stem cells without the need for embryonic tissues, (3) they are amenable to gene correction approaches, and (4) they are now routinely derived.

\section{DIRECTED DIFFERENTIATION OF IPSCS INTO LUNG EPITHELIUM}

Over the past decade, many groups contributed to major progress toward generating lung epithelial cells from iPSCs (Table 1). Directed differentiation refers to the approach of recapitulating, in vitro, the key embryonic developmental milestones that lead to the specification of the cell(s) of interest. This is typically achieved through the stepwise addition of signaling factors identified in mouse studies of organogenesis. The field of lung directed differentiation has evolved from generating relatively immature lung epithelial cells to recent reports of increasingly sophisticated protocols that produce relatively mature and functional lung epithelial cells that are currently being applied to lung disease modeling, drug screening and the first forays into in vivo transplantation.

In order to understand the directed differentiation process, a brief overview of lung development is first required. The lung develops from the foregut endoderm and is first identified by the expression of $N k x 2-1$, a key transcription factor. $N k x 2-1$ is first detected at E9.0 in mice and day 28 in human embryos (Lazzaro et al., 1991; Morrisey and Hogan, 2010). During the first stages of lung organogenesis $N k \times 2-1^{+}$cells form two primary lung buds and the adjacent foregut separates into two tubes, a ventral trachea and dorsal esophagus. During the pseudoglandular stage, the lung buds undergo branching morphogenesis and proximal-distal patterning. This process, controlled by reciprocal signaling between the lung epithelium and surrounding mesenchyme, gives rise to a highly branched airway tree composed of basal, secretory, multi-ciliated and neuroendocrine cells and an alveolar compartment composed of types 1 and 2 pneumocytes. A number of signaling pathways are involved in the epithelialmesenchymal interactions that control these stages of lung development including SHH, WNTs, FGFs, retinoic acid and BMPs (Hawkins et al., 2016).

To differentiate iPSCs into lung epithelial cells researchers seek to reproduce these key developmental events in vitro. The first major developmental stage in the road map of lung development is the formation of definitive endoderm. Mimicking the in vivo patterning of the primitive streak, the addition of the Nodal agonist Activin-A to iPSCs or ESCs produces a highly enriched population of endodermal cells that express classic endoderm markers (including FOXA2 and SOX17) (Kubo et al., 2004; D’Amour et al., 2005; Christodoulou et al., 2011). The protocols to generate definitive endoderm are now well established and form the basis of all endodermal differentiation protocols including lung, liver, pancreas and intestine. The next important developmental step is directing definitive endodermal cells $\left(F O X A 2^{+}\right)$toward an anteriorforegut fate $\left(F O X A 2^{+} / S O X 2^{+}\right)$, analogous to the anteriorposterior axis patterning in the primitive gut tube. The field of 
lung directed differentiation is relatively new and not surprisingly the published protocols from different groups vary significantly in terms of the timing and combination of growth factors and inhibitors applied at different stages. For example, differing approaches have achieved in vitro foregut patterning. In one method antagonism of BMP and TGF $\beta$ pathways after endoderm induction was identified as the most potent condition to maintain FOXA2 expression, and to induce the anterior endoderm marker SOX2 while suppressing a hindgut fate that expresses CDX2 (Green et al., 2011). The inclusion of BMP and/or TGF $\beta$ inhibition has been adopted by others (Longmire et al., 2012; Mou et al., 2012; Firth et al., 2014; Dye et al., 2015; Hawkins et al., 2017). Alternative approaches include the combination of FGF2 and SHH signaling (Wong et al., 2012). Lung specification is the next major developmental milestone and is indicated by the expression of NKX2-1 in foregut endoderm cells. Several groups have concluded that WNT, through recombinant WNT3a or glycogen synthase kinase 3 inhibitors, BMP4, and retinoic acid pathway activation are required for lung specification (Huang et al., 2013; Gotoh et al., 2014; Hawkins et al., 2017). Others have developed quite different approaches that led to specification of a lung program, for example using a combination of BMP and TGF $\beta$ inhibition, plus SHH and WNT activation (Dye et al., 2015). Early reports demonstrated lung competence of these cells via upregulation of differentiation markers over time. However, both proximal and distal lung markers were frequently present suggesting that the precise signals patterning lung progenitors toward proximal vs. distal fates and to specific differentiated cell types are incompletely known. Competence of these cells to differentiate into functional airway lineages was demonstrated by transitioning to air-liquid interface conditions used to differentiate primary HBECs, or by injecting the cells into the flank or kidney capsule of immune-deficient mice (Wong et al., 2012; Huang et al., 2013; Firth et al., 2014). More recently, there has been progress in generating lung organoids from iPSC-derived lung epithelium, reminiscent of the 3-D organization of lung tissue (Gotoh et al., 2014; Dye et al., 2015; Chen et al., 2017; Hawkins et al., 2017; Miller et al., 2018). In some cases, these protocols involve the co-development of mesodermal and endodermal compartments. To overcome the heterogeneity of cell types produced in these protocols, fluorescent lineage reporters or surface markers have been employed to prospectively isolate the lung epithelial cells of interest. Surface markers including Carboxypeptidase $\mathrm{M}$ or the combination of $\mathrm{CD} 47^{\mathrm{hi}} / \mathrm{CD} 26^{\text {lo }}$ were identified to isolate immature $N K X 2-1^{+}$lung epithelial cells and to generate lung epithelial organoids depleted of other endodermal and mesodermal cell types (Gotoh et al., 2014; Hawkins et al., 2017). Although less relevant as a cellbased therapy for CF, it is worth highlighting some of the most compelling progress toward generating relatively mature, functional type 2 pneumocytes from iPSCs. Two groups, adopting the approach of targeting fluorescent reporters to the endogenous SFTPC locus, developed similar protocols to isolate and propagate long term a population of SFTPC $^{+}$cells highly reminiscent of alveolar type 2 cells (Jacob et al., 2017; Yamamoto et al., 2017).

\section{DIRECTED DIFFERENTIATION OF IPSCS INTO AIRWAY EPITHELIUM}

To cure CF airway disease, a cell-based therapy would ideally replace the CFTR-expressing columnar luminal epithelial cells, including terminally differentiated multi-ciliated cells and perhaps ionocytes, but also the stem/progenitor cells that maintain the luminal cells. A number of groups have demonstrated the feasibility of generating CFTR expressing airway epithelium composed of multi-ciliated cells and cells reminiscent of basal and secretory cells (Wong et al., 2012; Firth et al., 2014; Konishi et al., 2016; McCauley et al., 2017). These airway epithelial cells broadly recapitulate the CFTR dysfunction seen in the primary cells of CF patients when interrogated using established CFTR functional assays including ion transport in Ussing chambers and forskolin-induced spheroid swelling. In an important proof-of-concept study, Crane et al., demonstrated the correction of the F508del mutation in iPSCs using zinc-finger nucleases and restoration of CFTR function in those cells after lung differentiation (Crane et al., 2015). Based on our current knowledge, an ideal iPSC-derived candidate cell for engraftment into CF airways is the airway basal cell. A number of groups have described the presence of a subset of basal-like cells after directed lung differentiation as evidenced by the expression of key basal cell markers (e.g., TP63, KRT5) (Dye et al., 2015; Konishi et al., 2016; Chen et al., 2017; Hawkins et al., 2017; McCauley et al., 2017). However, the efficient derivation of bonafide basal cells, as evidenced by transcriptional profiling and functional demonstration of differentiation into multi-ciliated and secretory cells comparable to those generated by primary basal cell controls, has not yet been convincingly achieved.

\section{IN VIVO ENGRAFTMENT OF iPSC-DERIVED LUNG EPITHELIAL CELLS}

Provided that it is possible to derive a candidate cell type in vitro, would that cell engraft and function once transplanted? This is a major question now facing this field and very little is known about the in vivo potential of iPSC-derived cells in the lung. Recently, the first report of human iPSC-derived lung epithelial cells engrafting in a murine lung injury model was described (Miller et al., 2018). Miller et al., identified conditions to capture and expand cells with a transcriptional profile similar to the multipotent cells of the developing lung bud tip. The iPSC-derived lung tip cells were delivered intratracheally into immunocompromised mice following airway injury with naphthalene. Engrafted cells persisted for up to 6 weeks after transplantation and these cells had adopted a predominantly airway and mostly secretory cell fate with rare multi-ciliated cells. This study is an important first step establishing the feasibility of using animal models to develop engraftment strategies, and suggests that the micro-environment 
or niche may play an important role in the cell fate decisions of transplanted cells.

\section{CHALLENGES FACING IPSCS AS A CELL-BASED THERAPY}

Despite the progress made in the field of iPSC directed differentiation into lung cells, there are major challenges facing the application of cell-based therapy for the treatment of CF. To date, the derivation of a pure population of airway epithelial cells from iPSCs in sufficient numbers to engraft in human airways has not yet been achieved. How will adequate numbers of differentiated cells be generated for patients? How safe are iPSC-derived lung epithelial cells? The same factors and culture conditions that allow for the unimpeded self-renewal and pluripotency also predispose to tumorigenicity; in fact, a survey of the exomes of 117 human iPSC lines identified nine with mutations in the tumor suppressor gene, TP53, with evidence that iPSCs with the mutation had a survival advantage (BenDavid and Benvenisty, 2011; Merkle et al., 2017). Other groups have confirmed that gene editing with CRISPR/Cas9 selects against cells with a normal p53 pathway (Haapaniemi et al., 2018; Ihry et al., 2018). Initially iPSCs were generated using viral vectors that randomly integrated into the genome (Takahashi and Yamanaka, 2006). This approach raised obvious concerns about the malignant potential of iPSCs if an important tumor suppressor locus was disrupted. A non-integrating episomalbased method, such as Sendai virus, is a more logical approach to derive clinical-grade iPSCs (Fusaki et al., 2009). The delivery of safe cells will require a robust and reproducible process to generate iPSCs and differentiated cells, compliant with relevant current good manufacturing practice (cGMP) and regulatory agency approval. Confirmation that the resulting cells are free of integrations and somatic mutations will be needed (Baghbaderani et al., 2015). Transplanted cells will require in vitro genecorrection to express functional CFTR. With reprogramming and passaging, and additional time needed to gene-edit and expand cells, the probability of somatic mutations will increase. Furthermore, the process of gene-editing brings additional risk of off-target double-stranded breaks with the potential of disrupting other genetic loci (Zhang et al., 2015). As the goal of cell-based therapy is to replace diseased endogenous lung epithelium with engineered cells, it will be essential to generate pure populations of lung epithelial cells that are highly similar to their in vivo counterparts. The field is relatively new and most reports have not focused on the non-lung cells that might also be produced during the differentiation process. For example, an iPSC line expressing GFP from the NKX2-1 locus (NKX2-1 ${ }^{\mathrm{GFP}}$ ) identified significant variability in the percentage of $\mathrm{GFP}^{+}$cells, and analysis of the GFP ${ }^{-}$population confirmed expression of liver and intestine markers (Hawkins et al., 2017; Serra et al., 2017). Even after a purification step to sort NKX2-1 ${ }^{\mathrm{GFP}}+$ cells, McCauley et al. applied single-cell RNA sequencing to airway and alveolar iPSC-derived organoids and identified distinct populations of non-lung endoderm including hepatic-like and gastric-like cells (McCauley et al., 2018). The quest to generate pure populations of well-defined lung epithelial cells will continue and be aided by powerful new techniques such as single-cell RNA sequencing and expanding knowledge of the transcriptional profile and signaling pathways involved in human lung development (Treutlein et al., 2014; Nikolić et al., 2017; Miller et al., 2018). The appropriate number of donor cells required to repopulate a sufficient portion of the diseased airway epithelium is unknown. CFTR levels $15-20 \%$ of normal airway expression may be enough to effectively treat CF airway disease (McKone et al., 2003). Building on these aforementioned advances, the ultimate final hurdle to a cell-based therapeutic approach for CF is engraftment.

\section{ENGRAFTMENT}

The gold standard for cell-based therapy is hematopoietic cell transplantation. This now commonplace and life-saving procedure relies on delivering hematopoietic progenitor cells after inducing tissue receptivity through marrow-ablative doses of cytotoxic agents and radiation. The term engraftment is used to describe the reconstitution of host bone marrow by donor cells. For CF, successful airway engraftment is thought of in similar terms, recipient airway priming, donor cell survival and regeneration of the airway epithelium (Figure 2). The ideal strategy to deliver a cell-based therapy for CF, or any lung disease, has yet to be developed and the prospect of deliberately injuring the lungs of CF recipients to ablate endogenous cells is daunting. An ideal engraftment strategy would involve the minimal airway injury necessary, in particular to the small airways, to promote a microenvironment conducive to long-lived engraftment of cells in numbers sufficient to restore CFTR function. There are many hurdles the scientific community must overcome to achieve human airway engraftment such as determining: (1) the most suitable cell type(s), (2) the methods to safely scale-up cell production, (3) the optimal injury, (4) supportive measures for oxygenation/ventilation and (5) methods to control mucus and infection to allow engraftment of cells. Despite these challenges, there are promising reports of effective cell therapies for other organ systems that support the overall feasibility of this approach. Based on pioneering work from the laboratory of Howard Green, autologous epidermal keratinocytes have been extensively evaluated as treatment for burns (Green et al., 1979; Ter Horst et al., 2018). Recently, transgenic autologous keratinocytes with a correct copy of a gene mutated in the blistering skin disease junctional epidermolysis bullosa were used to replace nearly the entire epidermis of a critically ill child with $60 \%$ skin loss, miraculously allowing hospital discharge and return to school (Hirsch et al., 2017). This remarkable achievement not only alleviated patient suffering, but also provided vital insights about epidermal keratinocyte stem cell dynamics, indicating the importance of long-lived stem cells for epidermal restoration. Additional experience comes from corneal limbal epithelial stem cell transplantation in which damage to one eye can be treated with autologous stem cells from the contralateral eye (Rama et al., 2017; Sasamoto et al., 2018). In the lung field, a number of groups have recently reported evidence of lung engraftment in animal models (Rosen et al., 2015; Vaughan et al., 2015; 
A

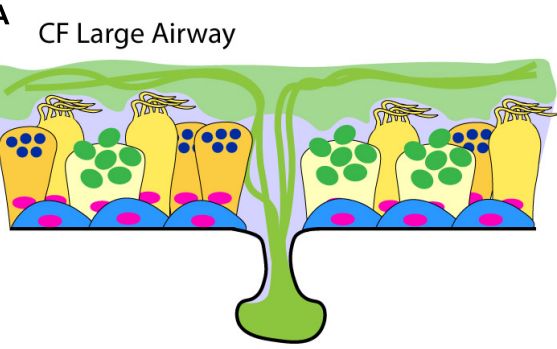

C Deliver CFTR-corrected cells

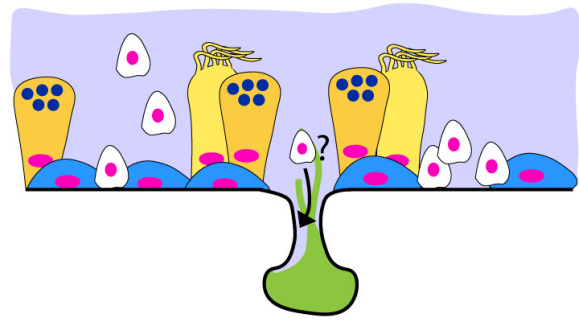

B

B Mucus removal and transient injury

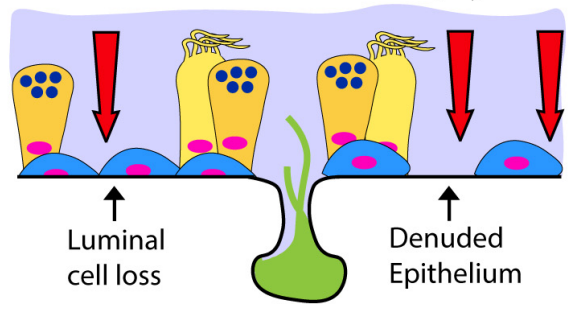

D Differentiation and functional restoration

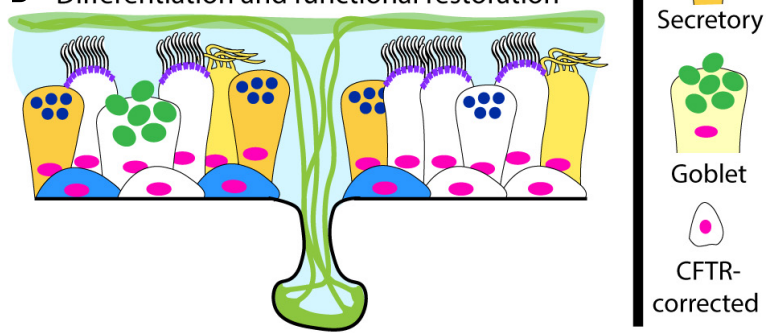

FIGURE 2 | A Cell-Based Therapy Model for CF. (A) The pre-treatment CF large airway. (B-D) A depiction of cell-based therapy in three steps: (B) Mucus removal and transient preconditioning of the airway epithelium, potentially requiring luminal epithelial surface cell loss and partial epithelial denudation; (C) Delivery of CFTR-corrected stem and progenitor cells to the surface epithelium and possibly the submucosal glands; (D) Differentiation of delivered CFTR-corrected cells into all relevant cell types, restoration of functional CFTR ion-transport and a return to normal airway physiology.

Ghosh et al., 2017; Nichane et al., 2017; Ma et al., 2018; Miller et al., 2018). Here we will briefly review this progress and highlight important next steps.

A number of injury models, including naphthalene, sulfur dioxide, radiation and detergents, have been developed to study the biology of the airway epithelium (Lamb and Reid, 1968; Plopper et al., 1992; Borthwick et al., 2001; Leblond et al., 2009; Rosen et al., 2015). It is unclear to what extent, if any, these models might be used in humans but they have provided a platform to study and develop engraftment strategies. Embryonic lung, both mouse and human, contain stem/progenitor populations with engraftment capacity (Rosen et al., 2015; Nichane et al., 2017). In one approach, intravenous administration of a single cell suspension of whole canalicular stage lung (mouse E15-16 or human week 20-22) into mice preconditioned with both naphthalene and total body irradiation, resulted in epithelial, mesenchymal, and endothelial patches of engrafted cells (Rosen et al., 2015). Higher rates of chimerism were detected in mouse-into-mouse compared to human-intomouse experiments. It is surprising that intravenous delivery of a mixture of embryonic lung cell types resulted in homing of cells to their unique anatomic compartments. Further work is required to understand the safety of this approach including the consequence of cells being delivered to the wrong compartment within the lung or even to other organs. In terms of an approach for CF, the majority of epithelial engrafted cells had an alveolar phenotype although some airway-like cells were detected and some expressed CFTR. Interestingly, the co-administration of mesenchymal and endothelial cells was associated with improved epithelial cell engraftment. The multitude of practical, ethical and political issues surrounding the use of fetal tissue make this an unlikely future option for cell-based therapy. However, iPSCs may provide access to autologous cells at embryonic time points with capacity to engraft (Miller et al., 2018). Adult airway epithelial cells can also engraft in the lung (Vaughan et al., 2015; Ghosh et al., 2017; Nichane et al., 2017). The environment induced by H1N1 influenza infection has garnered much interest for its engraftment potential (Kumar et al., 2011; Vaughan et al., 2015). The viral infection causes widespread damage to the airway and alveolar epithelium and activates rare immature $\left(\mathrm{TP} 3^{+} / \mathrm{KRT5}^{-}\right)$basal cells in the small airways (Yang et al., 2018). Orthotopic transplantation of a variety of airway epithelial cells into influenza-injured mice led to varying levels of engraftment (Vaughan et al., 2015). Perhaps most relevant to the CF field is a recent report of successful engraftment of primary airway basal cells into naphthalene injured mice (Ghosh et al., 2017). Transplanted mouse or human basal cells reconstituted patches of epithelium in the trachea and small airways with evidence of multi-lineage differentiation into secretory and multi-ciliated cells. Themes common to each of the above experiments include: (1) lung injury is required for engraftment of donor cells, (2) different injury models likely result in unique regenerative niches and (3) successful strategies to date suggest multipotent input donor cells are the most promising candidates for engraftment. Looking forward, a number of approaches might accelerate the field of cell-based therapy for lung disease. Engraftment after hematopoietic cell transplantation is monitored by sampling the peripheral blood. Assessing lung engraftment is far more challenging. Methods to interrogate whether donor cells are functionally integrated into the airway epithelium will be essential. Animal studies to optimize injury models and the efficiency, function and safety 
of engrafted cells are necessary, but are rate-limiting due to low throughput, particularly in larger animals. Developing non-lethal experimental methods, including targeted airway injury and bioluminescent reporter cell lines to track engrafted cells in real-time without the need for necropsy would increase the efficiency of animal engraftment studies.

Methods to incite a targeted, clinically tolerable airway epithelial injury have been tested in humans albeit not in the context of cell-based therapy. Bronchial thermoplasty, an FDA-approved treatment for refractory severe persistent asthma, delivers brief thermal energy to the airways via flexible bronchoscopy and leads to initial epithelial sloughing and a prolonged decrease in smooth muscle with improvement in asthma severity (Miller et al., 2005). In a small pilot study, airway delivery of a metered liquid nitrogen cryospray via bronchoscopy resulted in airway epithelial damage followed by regeneration (Slebos et al., 2017). An alternative approach, with potential for clinical translation, is targeted airway deepithelialization achieved by instilling mild detergents intratracheally (Dorrello et al., 2017). Despite the many limitations of these approaches in the context of $\mathrm{CF}$, including the small size and large number of airways needed to treat CF, they provide preliminary support for the feasibility of a human injury platform. The situation is further complicated for targeting CF in more advanced disease where successful cell-based therapy must also overcome a highly inflamed, architecturally distorted organ characterized by thick mucus and superinfection. Similar to the blood product and growth factor support necessary after hematopoietic cell transplant, lung engraftment strategies will likely require lung supportive measures. The advances and more widespread use of extracorporeal membrane oxygenation (ECMO) provides a means of supporting oxygenation during respiratory failure (Squiers et al., 2016). Advances in the technology to maintain human lungs using ex vivo lung perfusion (EVLP) may provide insights into supporting the injured and regenerating lung (Makdisi et al., 2017). Future approaches for cell-based therapy incorporating these evolving technologies may be necessary. Alternatively, devising injury-independent strategies to promote lung engraftment of therapeutic cells may be an avenue for future research and development.

\section{REFERENCES}

Baghbaderani, B. A., Tian, X., Neo, B. H., Burkall, A., Dimezzo, T., Sierra, G., et al. (2015). cGMP-manufactured human induced pluripotent stem cells are available for pre-clinical and clinical applications. Stem Cell Rep. 5, 647-659. doi: 10.1016/j.stemcr.2015.08.015

Ben-David, U., and Benvenisty, N. (2011). The tumorigenicity of human embryonic and induced pluripotent stem cells. Nat. Rev. Cancer 11, 268-277. doi: 10.1038/nrc3034

Borthwick, D. W., Shahbazian, M., Krantz, Q. T., Dorin, J. R., and Randell, S. H. (2001). Evidence for stem-cell niches in the tracheal epithelium. Am. J. Respir. Cell Mol. Biol. 24, 662-670. doi: 10.1165/ajrcmb.24. 6.4217

Bove, P. F., and Randell, S. H. (2015). "Comparative mammalian lung primary surface epithelial cell culture," in Comparative Biology of the Normal Lung,

\section{CONCLUSION}

To date, CF remains the most common life-limiting hereditary lung disease. Decades of work resulted in important strides to understand molecular mechanisms in CF and treatment options for many patients. Despite this progress, a subset of patients lack effective treatment options and cell-based therapies could theoretically cure CF lung disease. The ideal cell type for this purpose would repopulate the airway epithelium with autologous, functional, and CFTR-expressing cells. Progress in our understanding of airway epithelial biology and endogenous stem/progenitor populations has revealed a number of candidate cell types for airway regeneration, in particular basal cells. The recent revolution in gene-editing techniques means genetic correction of the CFTR mutation in basal cells will likely be achieved in the near future and would provide a source of autologous airway stem cells with the normal CFTR sequence. In the iPSC field, directed differentiation protocols have evolved from initial studies demonstrating the presence of immature lung-like cells to more recent reports of increasingly efficient protocols to derive functional alveolar and airway epithelial cells. We have detailed some of the major challenges that must be overcome both in terms of generating the cells of interest and engrafting those cells in a safe and effective manner. While there is work yet to be done, there is cautious optimism that a curative cell-based therapy for CF will be achieved in the future.

\section{AUTHOR CONTRIBUTIONS}

All authors contributed to this manuscript. In collaboration, AB, $\mathrm{FH}, \mathrm{RL}$, and SR wrote all sections of this review. RL illustrated the figures. All authors read, edited, and approved of the final version of the manuscript.

\section{FUNDING}

The authors received funding support from NIH grants T32HL0007025 (AB) and R01HL139799 (FH), Cystic Fibrosis Foundation grants RANDEL15XX0 (SR), RANDEL17XX0 (SR), and HAWKIN15XX0 (FH), and Emily's Entourage (FH and SR).

(Cambridge, MA: Academic Press), 129-139. doi: 10.1016/B978-0-12-4045774.00011-4

Butler, C. R., Hynds, R. E., Gowers, K. H. C., Lee, D. D. H., Brown, J. M., Crowley, C., et al. (2016). Rapid expansion of human epithelial stem cells suitable for airway tissue engineering. Am. J. Respir. Crit. Care Med. 194, 156-168. doi: 10.1164/rccm.201507-1414OC

Button, B., Cai, L.-H., Ehre, C., Kesimer, M., Hill, D. B., Sheehan, J. K., et al. (2012). A periciliary brush promotes the lung health by separating the mucus layer from airway epithelia. Science 337, 937-941. doi: 10.1126/science.1223012

Chen, Y.-W., Huang, S. X., de Carvalho, A. L. R. T., Ho, S.-H., Islam, M. N., Volpi, S., et al. (2017). A three-dimensional model of human lung development and disease from pluripotent stem cells. Nat. Cell Biol. 19, 542-549. doi: 10. 1038/ncb3510

Christodoulou, C., Longmire, T. A., Shen, S. S., Bourdon, A., Sommer, C. A., Gadue, P., et al. (2011). Mouse ES and iPS cells can form similar definitive 
endoderm despite differences in imprinted genes. J. Clin. Investig. 121, 23132325. doi: $10.1172 /$ JCI 43853

Crane, A. M., Kramer, P., Bui, J. H., Chung, W. J., Li, X. S., Gonzalez-Garay, M. L., et al. (2015). Targeted correction and restored function of the CFTR gene in cystic fibrosis induced pluripotent stem cells. Stem Cell Rep. 4, 569-577. doi: 10.1016/j.stemcr.2015.02.005

Cutting, G. R. (2014). Cystic fibrosis genetics: from molecular understanding to clinical application. Nat. Rev. Genet. 16, 45-56. doi: 10.1038/nrg3849

D'Amour, K. A., Agulnick, A. D., Eliazer, S., Kelly, O. G., Kroon, E., and Baetge, E. E. (2005). Efficient differentiation of human embryonic stem cells to definitive endoderm. Nat. Biotechnol. 23, 1534-1541. doi: 10.1038/nbt1163

Davies, J. C., Moskowitz, S. M., Brown, C., Horsley, A., Mall, M. A., McKone, E. F., et al. (2018). VX-659-tezacaftor-ivacaftor in patients with cystic fibrosis and one or two phe508del alleles. N. Engl. J. Med. 379, 1599-1611. doi: 10.1056/ NEJMoa 1807119

Dorrello, N. V., Guenthart, B. A., O’Neill, J. D., Kim, J., Cunningham, K., Chen, Y.-W., et al. (2017). Functional vascularized lung grafts for lung bioengineering. Sci. Adv. 3:e1700521. doi: 10.1126/sciadv.1700521

Dye, B. R., Hill, D. R., Ferguson, M. A., Tsai, Y.-H., Nagy, M. S., Dyal, R., et al. (2015). In vitro generation of human pluripotent stem cell derived lung organoids. eLife 4, 1999-1925. doi: 10.7554/eLife.05098

Evans, M. J., and Kaufman, M. H. (1981). Establishment in culture of pluripotential cells from mouse embryos. Nature 292, 154-156. doi: 10.1038/292154a0

Firth, A. L., Dargitz, C. T., Qualls, S. J., Menon, T., Wright, R., Singer, O., et al. (2014). Generation of multiciliated cells in functional airway epithelia from human induced pluripotent stem cells. Proc. Natl. Acad. Sci. U.S.A. 111, E1723-E1730. doi: 10.1073/pnas.1403470111

Fulcher, M. L., and Randell, S. H. (2013). Human nasal and tracheo-bronchial respiratory epithelial cell culture. Methods Mol. Biol. 945, 109-121. doi: 10.1007/ 978-1-62703-125-7_8

Fusaki, N., Ban, H., Nishiyama, A., Saeki, K., and Hasegawa, M. (2009). Efficient induction of transgene-free human pluripotent stem cells using a vector based on Sendai virus, an RNA virus that does not integrate into the host genome. Proc. Jpn. Acad. Series B Phys. Biol. Sci. 85, 348-362. doi: 10.2183/pjab. 85.348

Gentzsch, M., Boyles, S. E., Cheluvaraju, C., Chaudhry, I. G., Quinney, N. L., Cho, C., et al. (2017). Pharmacological rescue of conditionally reprogrammed cystic fibrosis bronchial epithelial cells. Am. J. Respir. Cell Mol. Biol. 56, 568-574. doi: 10.1165/rcmb.2016-0276MA

Ghosh, M., Ahmad, S., White, C. W., and Reynolds, S. D. (2017). Transplantation of airway epithelial stem/progenitor cells: a future for cell-based therapy. Am. J. Respir. Cell Mol. Biol. 56, 1-10. doi: 10.1165/rcmb.2016-0181MA

Gotoh, S., Ito, I., Nagasaki, T., Yamamoto, Y., Konishi, S., Korogi, Y., et al. (2014). Generation of alveolar epithelial spheroids via isolated progenitor cells from human pluripotent stem cells. Stem Cell Rep. 3, 394-403. doi: 10.1016/j.stemcr. 2014.07.005

Gray, T., Rundhaug, J., and Nettesheim, P. (1991). Critical variables controlling cell proliferation in primary cultures of rat tracheal epithelial cells. In Vitro cellular \& developmental biology. J. Tissue Cult. Assoc. 27A, 805-814. doi: 10.1007/BF02631247

Gray, T. E., Guzman, K., Davis, C. W., Abdullah, L. H., and Nettesheim, P. (1996). Mucociliary differentiation of serially passaged normal human tracheobronchial epithelial cells. Am. J. Respir. Cell Mol. Biol. 14, 104-112. doi: 10.1165/ajrcmb.14.1.8534481

Green, H., Kehinde, O., and Thomas, J. (1979). Growth of cultured human epidermal cells into multiple epithelia suitable for grafting. Proc. Natl. Acad. Sci. U.S.A. 76, 5665-5668. doi: 10.1073/pnas.76.11.5665

Green, M., Chen, A., Nostro, M.-C., d'Souza, S. L., Schaniel, C., Lemischka, I. R., et al. (2011). Generation of anterior foregut endoderm from human embryonic and induced pluripotent stem cells. Nat. Biotechnol. 29, 267-272. doi: 10.1038/ nbt.1788

Gurdon, J. B. (1962). The developmental capacity of nuclei taken from intestinal epithelium cells of feeding tadpoles. J. Embryol. Exp. Morphol. 10, 622-640.

Haapaniemi, E., Botla, S., Persson, J., Schmierer, B., and Taipale, J. (2018). CRISPRCas 9 genome editing induces a p53-mediated DNA damage response. Nat. Med. 24, 927-930. doi: 10.1038/s41591-018-0049-z

Hawkins, F., Kramer, P., Jacob, A., Driver, I., Thomas, D. C., McCauley, K. B., et al. (2017). Prospective isolation of NKX2-1-expressing human lung progenitors derived from pluripotent stem cells. J. Clin. Investig. 127, 2277-2294. doi: 10. 1172/JCI89950

Hawkins, F., Rankin, S. A., Kotton, D. N., and Zorn, A. M. (2016). “The genetic programs regulating embryonic lung development and induced pluripotent stem cell differentiation," in Fetal and Neonatal Lung Development, eds A. Jobe, J. Whitsett, and S. Abman (Cambridge: Cambridge University Press), 1-21. doi: 10.1017/СBO9781139680349.002

Hegab, A. E., Ha, V. L., Bisht, B., Darmawan, D. O., Ooi, A. T., Zhang, K. X., et al. (2014). Aldehyde dehydrogenase activity enriches for proximal airway basal stem cells and promotes their proliferation. Stem Cells Dev. 23, 664-675. doi: $10.1089 /$ scd.2013.0295

Hegab, A. E., Ha, V. L., Darmawan, D. O., Gilbert, J. L., Ooi, A. T., Attiga, Y. S., et al. (2012). Isolation and in vitro characterization of basal and submucosal gland duct stem/progenitor cells from human proximal airways. Stem Cells Transl. Med. 1, 719-724. doi: 10.5966/sctm.2012-0056

Hirsch, T., Rothoeft, T., Teig, N., Bauer, J. W., Pellegrini, G., De Rosa, L., et al. (2017). Regeneration of the entire human epidermis using transgenic stem cells. Nature 551, 327-332. doi: 10.1038/nature24487

Hoegger, M. J., Fischer, A. J., McMenimen, J. D., Ostedgaard, L. S., Tucker, A. J., Awadalla, M. A., et al. (2014). Impaired mucus detachment disrupts mucociliary transport in a piglet model of cystic fibrosis. Science 345, 818-822. doi: 10.1126/ science. 1255825

Hogan, B. L. M., Barkauskas, C. E., Chapman, H. A., Epstein, J. A., Jain, R., Hsia, C. C. W., et al. (2014). Repair and regeneration of the respiratory system: complexity, plasticity, and mechanisms of lung stem cell function. Cell Stem Cell 15, 123-138. doi: 10.1016/j.stem.2014.07.012

Hong, K. U., Reynolds, S. D., Watkins, S., Fuchs, E., and Stripp, B. R. (2004). Basal cells are a multipotent progenitor capable of renewing the bronchial epithelium. Am. J. Pathol. 164, 577-588. doi: 10.1016/S0002-9440(10)63147-1

Huang, S. X. L., Islam, M. N., O’Neill, J., Hu, Z., Yang, Y.-G., Chen, Y.-W., et al. (2013). Efficient generation of lung and airway epithelial cells from human pluripotent stem cells. Nat. Biotechnol. 32, 84-91. doi: 10.1038/nbt.2754

Ihry, R. J., Worringer, K. A., Salick, M. R., Frias, E., Ho, D., Theriault, K., et al. (2018). p53 inhibits CRISPR-Cas9 engineering in human pluripotent stem cells. Nat. Med. 24, 939-946. doi: 10.1038/s41591-018-0050-6

Jacob, A., Morley, M., Hawkins, F., McCauley, K. B., Jean, J. C., Heins, H., et al. (2017). Differentiation of human pluripotent stem cells into functional lung alveolar epithelial cells. Cell Stem Cell 21, 472.e10-488.e10. doi: 10.1016/j.stem. 2017.08.014

Jiang, Q., and Engelhardt, J. F. (1998). Cellular heterogeneity of CFTR expression and function in the lung: implications for gene therapy of cystic fibrosis. Eur. J. Hum. Genet. 6, 12-31. doi: 10.1038/sj.ejhg.5200158

Keating, D., Marigowda, G., Burr, L., Daines, C., Mall, M. A., McKone, E. F., et al. (2018). VX-445-tezacaftor-ivacaftor in patients with cystic fibrosis and one or two Phe508del alleles. N. Engl. J. Med. 379, 1612-1620. doi: 10.1056/ NEJMoa 1807120

Konishi, S., Gotoh, S., Tateishi, K., Yamamoto, Y., Korogi, Y., Nagasaki, T., et al. (2016). Directed induction of functional multi-ciliated cells in proximal airway epithelial spheroids from human pluripotent stem cells. Stem Cell Rep. 6, 18-25. doi: 10.1016/j.stemcr.2015.11.010

Kotton, D. N., and Morrisey, E. E. (2014). Lung regeneration: mechanisms, applications and emerging stem cell populations. Nat. Med. 20, 822-832. doi: 10.1038/nm.3642

Kubo, A., Shinozaki, K., Shannon, J. M., Kouskoff, V., Kennedy, M., Woo, S., et al. (2004). Development of definitive endoderm from embryonic stem cells in culture. Development 131, 1651-1662. doi: 10.1242/dev.01044

Kumar, P. A., Hu, Y., Yamamoto, Y., Hoe, N. B., Wei, T. S., Mu, D., et al. (2011). Distal airway stem cells yield alveoli in vitro and during lung regeneration following H1N1 influenza infection. Cell 147, 525-538. doi: 10.1016/j.cell.2011. 10.001

Lamb, D., and Reid, L. (1968). Mitotic rates, goblet cell increase and histochemical changes in mucus in rat bronchial epithelium during exposure to sulphur dioxide. J. Pathol. Bacteriol. 96, 97-111. doi: 10.1002/path.1700960111

Lazzaro, D., Price, M., de Felice, M., and Di Lauro, R. (1991). The transcription factor TTF-1 is expressed at the onset of thyroid and lung morphogenesis and in restricted regions of the foetal brain. Development 113, 1093-1104.

Leblond, A.-L., Naud, P., Forest, V., Gourden, C., Sagan, C., Romefort, B., et al. (2009). Developing cell therapy techniques for respiratory disease: intratracheal 
delivery of genetically engineered stem cells in a murine model of airway injury. Hum. Gene Ther. 20, 1329-1343. doi: 10.1089/hum.2009.035

Lechner, J. F., Haugen, A., Autrup, H., McClendon, I. A., Trump, B. F., and Harris, C. C. (1981). Clonal growth of epithelial cells from normal adult human bronchus. Cancer Res. 41, 2294-2304.

Lechner, J. F., and LaVeck, M. A. (1985). A serum-free method for culturing normal human bronchial epithelial cells at clonal density. J. Tiss. Cult. Methods 9, 43-48. doi: 10.1007/BF01797773

Lee, J.-H., and Rawlins, E. L. (2018). Developmental mechanisms and adult stem cells for therapeutic lung regeneration. Dev. Biol. 433, 166-176. doi: 10.1016/j. ydbio.2017.09.016

Lee, J.-H., Tammela, T., Hofree, M., Choi, J., Marjanovic, N. D., Han, S., et al. (2017). Anatomically and functionally distinct lung mesenchymal populations marked by Lgr5 and Lgr6. Cell 170, 1149.e-1163.e. doi: 10.1016/j.cell.2017. 07.028

Liu, J. Y., Nettesheim, P., and Randell, S. H. (1994). Growth and differentiation of tracheal epithelial progenitor cells. Am. J. Physiol. 266(3 Pt 1), L296-L307. doi: 10.1152/ajplung.1994.266.3.L296

Liu, X., Krawczyk, E., Suprynowicz, F. A., Palechor-Ceron, N., Yuan, H., Dakic, A., et al. (2017). Conditional reprogramming and long-term expansion of normal and tumor cells from human biospecimens. Nat. Protoc. 12, 439-451. doi: 10.1038/nprot.2016.174

Longmire, T. A., Ikonomou, L., Hawkins, F., Christodoulou, C., Cao, Y., Jean, J. C., et al. (2012). Efficient derivation of purified lung and thyroid progenitors from embryonic stem cells. Stem Cell 10, 398-411. doi: 10.1016/j.stem.2012.01.019

Lynch, T. J., Anderson, P. J., Rotti, P. G., Tyler, S. R., Crooke, A. K., Choi, S. H., et al. (2018). Submucosal gland myoepithelial cells are reserve stem cells that can regenerate mouse tracheal epithelium. Cell Stem Cell 22, 653.e5-667.e5. doi: 10.1016/j.stem.2018.04.007

Ma, Q., Ma, Y., Dai, X., Ren, T., Fu, Y., Liu, W., et al. (2018). Regeneration of functional alveoli by adult human SOX9+ airway basal cell transplantation. Protein Cell 9, 267-282. doi: 10.1007/s13238-018-0506-y

Makdisi, G., Makdisi, T., Jarmi, T., and Caldeira, C. C. (2017). Ex vivo lung perfusion review of a revolutionary technology. Ann. Transl. Med. 5, 343-343. doi: $10.21037 / \mathrm{atm} .2017 .07 .17$

McCauley, K. B., Alysandratos, K.-D., Jacob, A., Hawkins, F., Caballero, I. S., Vedaie, M., et al. (2018). Single-cell transcriptomic profiling of pluripotent stem cell-derived SCGB3A2+ airway epithelium. Stem Cell Rep. 10, 1579-1595. doi: 10.1016/j.stemcr.2018.03.013

McCauley, K. B., Hawkins, F., Serra, M., Thomas, D. C., Jacob, A., and Kotton, D. N. (2017). Efficient derivation of functional human airway epithelium from pluripotent stem cells via temporal regulation of wnt signaling. Cell Stem Cell 20, 844.e6-857.e6. doi: 10.1016/j.stem.2017.03.001

McKone, E. F., Emerson, S. S., Edwards, K. L., and Aitken, M. L. (2003). Effect of genotype on phenotype and mortality in cystic fibrosis: a retrospective cohort study. Lancet 361, 1671-1676. doi: 10.1016/S0140-6736(03) $13368-5$

Merkle, F. T., Ghosh, S., Kamitaki, N., Mitchell, J., Avior, Y., Mello, C., et al. (2017). Human pluripotent stem cells recurrently acquire and expand dominant negative P53 mutations. Nature 545, 229-233. doi: 10.1038/nature22312

Miller, A. J., Hill, D. R., Nagy, M. S., Aoki, Y., Dye, B. R., Chin, A. M., et al. (2018). InVitro induction and InVivo engraftment of lung bud tip progenitor cells derived from human pluripotent stem cells. Stem Cell Rep. 10, 101-119. doi: 10.1016/j.stemcr.2017.11.012

Miller, J. D., Cox, G., Vincic, L., Lombard, C. M., Loomas, B. E., and Danek, C. J. (2005). A prospective feasibility study of bronchial thermoplasty in the human airway. Chest 127, 1999-2006. doi: 10.1378/chest.127.6.1999

Montoro, D. T., Haber, A. L., Biton, M., Vinarsky, V., Lin, B., Birket, S. E., et al. (2018). A revised airway epithelial hierarchy includes CFTR-expressing ionocytes. Nature 560, 319-324. doi: 10.1038/s41586-018-0393-7

Morrisey, E. E., and Hogan, B. L. M. (2010). Preparing for the first breath: genetic and cellular mechanisms in lung development. Dev. Cell 18, 8-23. doi: 10.1016/ j.devcel.2009.12.010

Mou, H., Vinarsky, V., Tata, P. R., Brazauskas, K., Choi, S. H., Crooke, A. K., et al. (2016). Dual SMAD signaling inhibition enables long-term expansion of diverse epithelial basal cells. Cell Stem Cell 19, 217-231. doi: 10.1016/j.stem.2016.05.012

Mou, H., Zhao, R., Sherwood, R., Ahfeldt, T., Lapey, A., Wain, J., et al. (2012). Generation of multipotent lung and airway progenitors from mouse ESCs and patient-specific cystic fibrosis iPSCs. Cell Stem Cell 10, 385-397. doi: 10.1016/j. stem.2012.01.018

Neuberger, T., Burton, B., Clark, H., and Van Gf. (2011). Use of primary cultures of human bronchial epithelial cells isolated from cystic fibrosis patients for the pre-clinical testing of CFTR modulators. Methods Mol. Biol. 741, 39-54. doi: 10.1007/978-1-61779-117-8_4

Nichane, M., Javed, A., Sivakamasundari, V., Ganesan, M., Ang, L. T., Kraus, P., et al. (2017). Isolation and 3D expansion of multipotent Sox9+ mouse lung progenitors. Nat. Methods 14, 1205-1212. doi: 10.1038/nmeth.4498

Nikolić, M. Z., Caritg, O., Jeng, Q., Johnson, J.-A., Sun, D., Howell, K. J., et al. (2017). Human embryonic lung epithelial tips are multipotent progenitors that can be expanded in vitro as long-term self-renewing organoids. eLife 6:e26575. doi: 10.7554/eLife.26575

Pardo-Saganta, A., Tata, P. R., Law, B. M., Saez, B., Chow, R. D.-W., Prabhu, M., et al. (2015). Parent stem cells can serve as niches for their daughter cells. Nature 523, 597-601. doi: 10.1038/nature14553

Peters-Hall, J. R., Coquelin, M. L., Torres, M. J., LaRanger, R., Alabi, B. R., Sho, S., et al. (2018). Long-term culture and cloning of primary human bronchial basal cells that maintain multipotent differentiation capacity and CFTR channel function. Am. J. Physiol. Lung Cell. Mol. Physiol. 315, L313-L327. doi: 10.1152/ ajplung.00355.2017

Plasschaert, L. W., Žilionis, R., Choo-Wing, R., Savova, V., Knehr, J., Roma, G., et al. (2018). A single-cell atlas of the airway epithelium reveals the CFTR-rich pulmonary ionocyte. Nature 3, 545-523. doi: 10.1038/s41586-018-0394-6

Plopper, C. G., Suverkropp, C., Morin, D., Nishio, S., and Buckpitt, A. (1992). Relationship of cytochrome P-450 activity to clara cell cytotoxicity. i. histopathologic comparison of the respiratory tract of mice, rats and hamsters after parenteral administration of naphthalene. J. Pharmacol. Exp. Ther. 261, 353-363.

Pollock, K., Albares, L., Wendt, C., and Hubel, A. (2013). Isolation of fibroblasts and epithelial cells in bronchoalveolar lavage (BAL). Exp. Lung Res. 39, 146-154. doi: 10.3109/01902148.2013.781720

Rama, P., Ferrari, G., and Pellegrini, G. (2017). Cultivated limbal epithelial transplantation. Curr. Opin. Ophthalmol. 28, 387-389. doi: 10.1097/ICU. 0000000000000382

Ramsey, B. W., Davies, J., McElvaney, N. G., Tullis, E., Bell, S. C., Dřevínek, P., et al. (2011). A CFTR potentiator in patients with cystic fibrosis and the G551D mutation. N. Engl. J. Med. 365, 1663-1672. doi: 10.1056/NEJMoa1105185

Randell, S. H., Boucher, R. C., and University of North Carolina Virtual Lung Group. (2006). Effective mucus clearance is essential for respiratory health. Am. J. Respir. Cell Mol. Biol. 35, 20-28. doi: 10.1165/rcmb.2006-0082SF

Randell, S. H., Burns, K., and Boucher, R. C. (2009). Epithelial Cells. New York, NY: Elsevier Ltd., 201-210. doi: 10.1016/B978-0-12-374001-4.00016-X

Ratjen, F., Bell, S. C., Rowe, S. M., Goss, C. H., Quittner, A. L., and Bush, A. (2015). Cystic fibrosis. Nat. Rev. Dis. Primers 1;15010. doi: 10.1038/nrdp.2015.10

Rock, J. R., Onaitis, M. W., Rawlins, E. L., Lu, Y., Clark, C. P., Xue, Y., et al. (2009). Basal cells as stem cells of the mouse trachea and human airway epithelium. Proc. Natl. Acad. Sci. U.S.A. 106, 12771-12775. doi: 10.1073/pnas.090685 0106

Roesch, E. A., Nichols, D. P., and Chmiel, J. F. (2018). Inflammation in cystic fibrosis: an update. Pediatr. Pulmonol. 23, S30-S50. doi: 10.1002/ppul.24129

Rosen, C., Shezen, E., Aronovich, A., Klionsky, Y. Z., Yaakov, Y., Assayag, M., et al. (2015). Preconditioning allows engraftment of mouse and human embryonic lung cells, enabling lung repair in mice. Nat. Med. 21, 869-879. doi: 10.1038/ nm.3889

Rosenow, T., Ramsey, K., Turkovic, L., Murray, C. P., Mok, L. C., Hall, G. L., et al. (2017). Air trapping in early cystic fibrosis lung disease-Does CT tell the full story? Pediatr. Pulmonol. 52, 1150-1156. doi: 10.1002/ppul.23754

Rowe, S. M., Daines, C., Ringshausen, F. C., Kerem, E., Wilson, J., Tullis, E., et al. (2017). Tezacaftor-ivacaftor in residual-function heterozygotes with cystic fibrosis. N. Engl. J. Med. 377, 2024-2035. doi: 10.1056/NEJMoa1709847

Sasamoto, Y., Ksander, B. R., Frank, M. H., and Frank, N. Y. (2018). Repairing the corneal epithelium using limbal stem cells or alternative cell-based therapies. Expert Opin. Biol. Ther. 18, 505-513. doi: 10.1080/14712598.2018.1443442

Schoch, K. G., Lori, A., Burns, K. A., Eldred, T., Olsen, J. C., and Randell, S. H. (2004). A subset of mouse tracheal epithelial basal cells generates large colonies in vitro. Am. J. Physiol. Lung Cell. Mol. Physiol. 286, L631-L642. doi: 10.1152/ ajplung.00112.2003 
Serra, M., Alysandratos, K.-D., Hawkins, F., McCauley, K. B., Jacob, A., Choi, J., et al. (2017). Pluripotent stem cell differentiation reveals distinct developmental pathways regulating lung- versus thyroid-lineage specification. Development 144, 3879-3893. doi: 10.1242/dev.150193

Slebos, D.-J., Breen, D., Coad, J., Klooster, K., Hartman, J., Browning, R., et al. (2017). Safety and histological effect of liquid nitrogen metered spray cryotherapy in the lung. Am. J. Respir. Crit. Care Med. 196, 1351-1352. doi: 10.1164/rccm.201611-2220LE

Smith, A. G. (2001). Embryo-derived stem cells: of mice and men. Ann. Rev. Cell Dev. Biol. 17, 435-462. doi: 10.1146/annurev.cellbio.17.1.435

Solter, D., Skreb, N., and Damjanov, I. (1970). Extrauterine growth of mouse egg cylinders results in teratoma formation. Nature 227, 503-504. doi: 10.1038/ $227503 \mathrm{a} 0$

Song, H., Yao, E., Lin, C., Gacayan, R., Chen, M.-H., and Chuang, P.-T. (2012). Functional characterization of pulmonary neuroendocrine cells in lung development, injury, and tumorigenesis. Proc. Natl. Acad. Sci. U.S.A. 109, 17531-17536. doi: 10.1073/pnas.1207238109

Squiers, J. J., Lima, B., and DiMaio, J. M. (2016). Contemporary extracorporeal membrane oxygenation therapy in adults: fundamental principles and systematic review of the evidence. J. Thorac. Cardiovasc. Surg. 152, 20-32. doi: 10.1016/j.jtcvs.2016.02.067

Stevens, L. C. (1970). The development of transplantable teratocarcinomas from intratesticular grafts of pre- and post-implantation mouse embryos. Dev. Biol. 21, 364-382. doi: 10.1016/0012-1606(70)90130-2

Stoltz, D. A., Meyerholz, D. K., and Welsh, M. J. (2015). Origins of cystic fibrosis lung disease. N. Engl. J. Med. 372, 351-362. doi: 10.1056/NEJMra1300109

Suprynowicz, F. A., Upadhyay, G., Krawczyk, E., Kramer, S. C., Hebert, J. D., Liu, X., et al. (2012). Conditionally reprogrammed cells represent a stem-like state of adult epithelial cells. Proc. Natl. Acad. Sci. U.S.A. 109, 20035-20040. doi: $10.1073 /$ pnas. 1213241109

Takahashi, K., Tanabe, K., Ohnuki, M., Narita, M., Ichisaka, T., Tomoda, K., et al. (2007). Induction of pluripotent stem cells from adult human fibroblasts by defined factors. Cell 131, 861-872. doi: 10.1016/j.cell.2007.11.019

Takahashi, K., and Yamanaka, S. (2006). Induction of pluripotent stem cells from mouse embryonic and adult fibroblast cultures by defined factors. Cell 126, 663-676. doi: 10.1016/j.cell.2006.07.024

Tata, A., Kobayashi, Y., Chow, R. D., Tran, J., Desai, A., Massri, A. J., et al. (2018). Myoepithelial cells of submucosal glands can function as reserve stem cells to regenerate airways after injury. Cell Stem Cell 22, 668.e6-683.e6. doi: 10.1016/j. stem.2018.03.018

Tata, P. R., Mou, H., Pardo-Saganta, A., Zhao, R., Prabhu, M., Law, B. M., et al. (2013). Dedifferentiation of committed epithelial cells into stem cells in vivo. Nature 503, 218-223. doi: 10.1038/nature12777

Tata, P. R., and Rajagopal, J. (2017). Plasticity in the lung: making and breaking cell identity. Development 144, 755-766. doi: 10.1242/dev.143784

Taylor-Cousar, J. L., Jain, M., Barto, T. L., Haddad, T., Atkinson, J., Tian, S., et al. (2018). Lumacaftor/ivacaftor in patients with cystic fibrosis and advanced lung disease homozygous for F508del-CFTR. J. Cyst. Fibros. 17, 228-235. doi: 10.1016/j.jcf.2017.09.012

Ter Horst, B., Chouhan, G., Moiemen, N. S., and Grover, L. M. (2018). Advances in keratinocyte delivery in burn wound care. Adv. Drug Deliv. Rev. 123, 18-32. doi: 10.1016/j.addr.2017.06.012
Treutlein, B., Brownfield, D. G., Wu, A. R., Neff, N. F., Mantalas, G. L., Espinoza, F. H., et al. (2014). Reconstructing lineage hierarchies of the distal lung epithelium using single-cell RNA-seq. Nature 509, 371-375. doi: 10.1038/ nature 13173

Vaughan, A. E., Brumwell, A. N., Xi, Y., Gotts, J. E., Brownfield, D. G., Treutlein, B., et al. (2015). Lineage-negative progenitors mobilize to regenerate lung epithelium after major injury. Nature 517, 621-625. doi: 10.1038/ nature 14112

Watson, J. K., Rulands, S., Wilkinson, A. C., Wuidart, A., Ousset, M., Van Keymeulen, A., et al. (2015). Clonal dynamics reveal two distinct populations of basal cells in slow-turnover airway epithelium. Cell Rep. 12, 90-101. doi: 10.1016/j.celrep.2015.06.011

Widdicombe, J. H., and Wine, J. J. (2015). Airway gland structure and function. Physiol. Rev. 95, 1241-1319. doi: 10.1152/physrev.00039.2014

Wong, A. P., Bear, C. E., Chin, S., Pasceri, P., Thompson, T. O., Huan, L.-J., et al. (2012). Directed differentiation of human pluripotent stem cells into mature airway epithelia expressing functional CFTR protein. Nat. Biotechnol. 30, 876-882. doi: 10.1038/nbt.2328

Yamamoto, Y., Gotoh, S., Korogi, Y., Seki, M., Konishi, S., Ikeo, S., et al. (2017). Long-term expansion of alveolar stem cells derived from human iPS cells in organoids. Nat. Methods 14, 1097-1106. doi: 10.1038/nmeth. 4448

Yang, Y., Riccio, P., Schotsaert, M., Mori, M., Lu, J., Lee, D.-K., et al. (2018). Spatialtemporal lineage restrictions of embryonic p63+ progenitors establish distinct stem cell pools in adult airways. Dev. Cell 44, 752.e4-761.e4. doi: 10.1016/j. devcel.2018.03.001

Zepp, J. A., Zacharias, W. J., Frank, D. B., Cavanaugh, C. A., Zhou, S., Morley, M. P., et al. (2017). Distinct mesenchymal lineages and niches promote epithelial selfrenewal and myofibrogenesis in the lung. Cell 170, 1134.e10-1148.e10. doi: 10.1016/j.cell.2017.07.034

Zhang, C., Lee, H. J., Shrivastava, A., Wang, R., McQuiston, T. J., Challberg, S. S., et al. (2018). Long-term in vitro expansion of epithelial stem cells enabled by pharmacological inhibition of PAK1-ROCK-Myosin II and TGF- $\beta$ signaling. Cell Rep. 25, 598-610. doi: 10.1016/j.celrep.2018.09.072

Zhang, F., Wen, Y., and Guo, X. (2014). CRISPR/Cas9 for genome editing: progress, implications and challenges. Hum. Mol. Genet. 23, R40-R46. doi: 10.1093/hmg/ddu125

Zhang, X.-H., Tee, L. Y., Wang, X.-G., Huang, Q.-S., and Yang, S.-H. (2015). Off-target effects in CRISPR/Cas9-mediated genome engineering. Mol. Ther. Nucleic Acids 4:e264. doi: 10.1038/mtna.2015.37

Conflict of Interest Statement: The authors declare that the research was conducted in the absence of any commercial or financial relationships that could be construed as a potential conflict of interest.

Copyright (c) 2019 Berical, Lee, Randell and Hawkins. This is an open-access article distributed under the terms of the Creative Commons Attribution License (CC BY). The use, distribution or reproduction in other forums is permitted, provided the original author(s) and the copyright owner(s) are credited and that the original publication in this journal is cited, in accordance with accepted academic practice. No use, distribution or reproduction is permitted which does not comply with these terms. 